\title{
Structure Seismic Design and Shaking Table Experiment Research
}

\author{
Status \\ Dejun Mao \\ School of Civil Engineering, Southwest Jiaotong University, Chengdu, Sichuan, 610031, China \\ 541089451@qq.com
}

Key words: Structure seismic;Design method;Shaking table test;Literature review.

Abstract. This paper analyzed the principle of performance-based seismic design method, compared and analyzed the performance-based seismic design method and the bearing capacity-based seismic design method, introduced seismic design methods of structure design code of several major countries in the world, analyzed the research status and main advantages and disadvantages of shaking table test, summarized the problems existing in the current research and the future research directions.

\section{Introduction}

The earthquakes and various earthquake-induced disasters cause a lot of casualties and huge property losses. There are signs that the human understanding of engineering structure seismic performance still lack enough, therefore, the study of structural seismic design and seismic simulation has been paid more and more attention by researchers $[1,10]$. The article summarized and analyzed the structural seismic design method and structural shaking table test research.

\section{Structural seismic design method}

Performance-based seismic design method. In the early 1990s, American scholars first put forward the concept of performance-based seismic design method [1]. The method emphasizes the grasp of the nonlinear deformation of building when subjected to large earthquake, focus on the overall system of the building, structural components, non-structural components and ancillary equipment in the entire life cycle of the various stages of seismic performance, its contents involve seismology, civil engineering, socioeconomics and other disciplines. Essentially, performance-based seismic design is based on a variety of limit state design methods to analyze the whole process of structure stress [2].

Performance-based seismic design must first determine the performance target of the structure, at present mention more are the level 4 and level 5 performance target partition, the details are shown in table 1 and table 2 respectively [1,4]. According to the performance target to complete the appropriate site selection and concept design, and then according to the selected performance goals, using the appropriate design method for structural design, perform a performance evaluation of the structure, provide the actual performance level. 
Table 1 The four-class classification of structural seismic performance level

\begin{tabular}{|c|c|c|}
\hline $\begin{array}{c}\text { Seismic } \\
\text { performance level }\end{array}$ & $\begin{array}{c}\text { General } \\
\text { description }\end{array}$ & Structural damage and use function situation \\
\hline Level 1 & $\begin{array}{l}\text { Basically } \\
\text { intact }\end{array}$ & $\begin{array}{l}\text { No permanent side shift, structure basic maintain the original } \\
\text { strength and stiffness, structural components and non-structural } \\
\text { components are not substantially damaged, all important } \\
\text { equipment still work normally. }\end{array}$ \\
\hline Level 2 & $\begin{array}{l}\text { Minor } \\
\text { damage }\end{array}$ & $\begin{array}{l}\text { No permanent side shift, structure basic maintain the original } \\
\text { strength and stiffness, structural components and non-structural } \\
\text { components are slightly damaged, the elevator can be restarted, } \\
\text { the fire protection measures are effective. }\end{array}$ \\
\hline Level 3 & Life safety & $\begin{array}{l}\text { All floors have residual strength and stiffness, the components } \\
\text { that bear the gravitational load are still work, outside the wall } \\
\text { plane failure or daughter wall collapse does not occur, have a } \\
\text { permanent side shift, partition wall damaged, construction } \\
\text { restoration costs may be high. }\end{array}$ \\
\hline Level 4 & $\begin{array}{c}\text { Not } \\
\text { collapsed }\end{array}$ & $\begin{array}{l}\text { Almost have no residual stiffness and strength, but the pillars } \\
\text { and walls that bear the load are still work, have large } \\
\text { permanent side shift, some exports are blocked, the inner wall } \\
\text { and the unsupported daughter wall have either begun or failed, } \\
\text { the building is about to collapse. }\end{array}$ \\
\hline
\end{tabular}

Table 2 The five-class classification of structural seismic performance level

\begin{tabular}{|c|c|c|}
\hline $\begin{array}{l}\text { Performance } \\
\text { level }\end{array}$ & Situation of personnel safety and usage & $\begin{array}{l}\text { Structural damage } \\
\text { situation }\end{array}$ \\
\hline Level 1 & $\begin{array}{l}\text { Structure functional perfection, personnel } \\
\text { safety, can be used immediately. }\end{array}$ & Basically intact \\
\hline Level 2 & After a little maintenance can be used & Minor damage \\
\hline Level 3 & The structure is destroyed, need a lot of repair & Medium damage \\
\hline Level 4 & $\begin{array}{l}\text { Structure occur irreparable damage, but not } \\
\text { collapsed. }\end{array}$ & Serious damage \\
\hline Level 5 & The structure collapsed & Basic collapsed \\
\hline
\end{tabular}

Currently, performance-based design method theory is not yet mature, need to carry out more theoretical and experimental research to improve its theoretical system, even for the displacement-based design method which is studied more, its lateral shift mode selection, equivalent single-degree-of-freedom system transform, the determination of the performance limit value and the neglect of the higher mode effect, etc, directly or indirectly affect the accuracy of the displacement-based design method, also need to continue to study and improve.

Comparison of performance-based seismic design method and bearing capacity-based seismic design method. The traditional seismic design method is based on the design of bearing capacity, the main differences between the performance-based seismic design method and bearing capacity-based seismic design method are as follows [2]:

(1) Structural seismic design is no longer just a given probability meaning, but is introduced into the decision-making mechanism.

(2) The seismic performance of the structure is expressed quantitatively by structural deformation, energy or economic parameters indexes. 
(3) Application of deformation-based elasto-plastic analysis method.

(4) Consider the multi-level seismic defense to increase the reliability of structural seismic design.

(5) By considering the structure component, the nonstructural component and accessories in the function requirement of the different stages throughout the life cycle, as important facility for the protection of buildings, reduce the maintenance time and maintain the continuity of the building function methods and means, to ensure that the building in the entire life cycle of the comprehensive economic benefits.

Specification design methods. China 'code for seismic design of buildings' GB50011-2001 implemented in 2001 put forward three-level fortification and two-stage seismic design ideas, which contains some of the performance-based design ideas. 'Code for seismic design of buildings' GB50011-2010 on the concept of design requirements also made a further, more in line with the actual regulations, making the concept of design in the application of the project more specifically fell to reality [8].

The European code for seismic design that is Eurocode 8 plays a very important role in seismic design of building structures, which contains detailed investigation and practice results of seismic design parameters in different regions. The EC8 aims to reduce earthquake damage to the building, protect people's life safety and ensure that the important buildings after the earthquake are still available [8]. Its seismic fortification goal is a double-level fortification goal, that is do not collapse fortification goal and limit damage fortification goal. In the chapter 4 of the code principle, there are some clear provisions for the structure seismic concept design.

Japan as early as 1910s late began building seismic research, formed a unique and is recognized as the most stringent architectural seismic design system. Although the Japanese code in the small earthquake design do not mention the 'strong column weak beam' concept, but the 'strong shear weak bending' thought runs through more thoroughly [10]. In the Japanese specification, the seismic design of the general building is design calculated respectively by the two-step design according to the small earthquake and the large earthquake, specifically including the first step based on the elastic theory (allowable stress method) to carry out the seismic design of small earthquake, to determine the initial structure size and section reinforcement. The second step is based on the elastic-plastic method for seismic calculation of large earthquake, to ensure the structure of the anti-collapse ability. Japan put two step design respectively referred to as 'primary design' and 'secondary design'.

\section{Structure shaking table model test}

Shaking table introduction. At present, most of the shaking table can only carry out scale model experiment. There are strict requirements for the dynamic similarity condition of the test object. The main drive modes of the shaking table are electromagnetic drive and electro-hydraulic servo drive, the current commonly used electro-hydraulic servo seismic simulating apparatus system is mainly composed of the hydraulic source system, exciter, servo analog controller, table and computer control system, as shown in figure 1. 


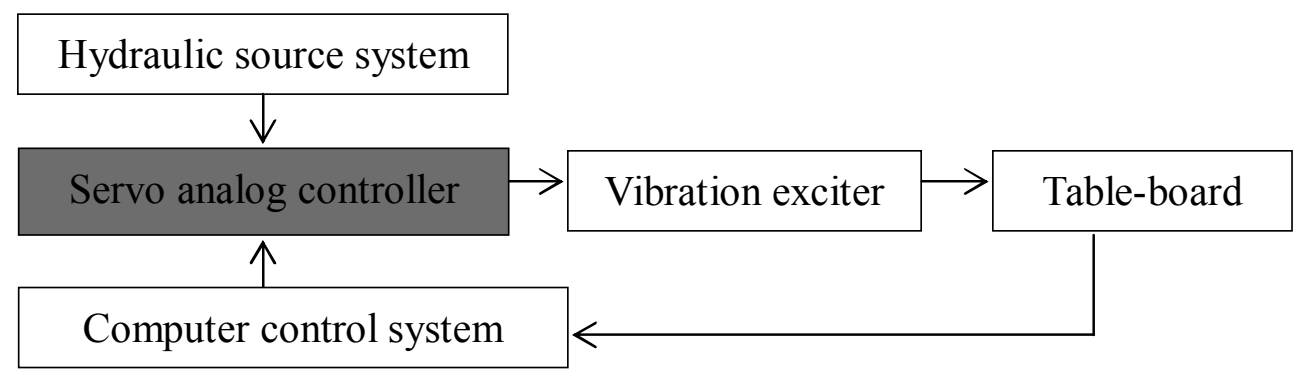

Fig. 1. Schematic diagram of earthquake simulation shaking table system

After several decades of development, the seismic simulation shaking table has increasingly developed the following three trends, namely, the development of large-scale full-scale test, the development of seismic simulation shaking table array and the development of all-digital control technology [6].

Some universities and research institutes in China have built a variety of seismic simulation platforms, Such as Tongji University, Fuzhou University, Chongqing Traffic Research and Design Institute, Beijing University of Technology, National Seismological Institute of Engineering Mechanics, Kunming University of Science and Technology and Central South University, these seismic simulation platforms have played a huge role in the development of engineering seismic research in China.

Structure shaking table test types. According to the object and purpose of the shaking table test, Structural shaking table test can generally be divided into three types [6]:

The first type is the test for determining the seismic performance of a particular structure, this type of shaking table test research contents are the coordination of the internal components of the structure under earthquake action, the overall seismic performance and dynamic characteristics of the structure etc. The prototype of this type of test will not be put into practical construction, usually use large-scale model to fully understand the interaction between structural components.

The second type of test prototype building is generally design completed high-rise building or super-standard building, this kind of building is characterized by a large volume of space, so due to the load restrict of vibration table, usually use small scale model to carry out the test, the purpose of the test is generally to determine the structural dynamic characteristics, study the natural frequency of structure, period, in order to compare with the site characteristics, find the weak links of the structure, so as to improve the design.

The purposes of the third type of test are generally to verify the suitability of a particular structure of the calculation method or a theory of the structure. The model similarity ratio of the structure is usually between the first two structures.

The advantages and disadvantages of structure shaking table test. The use of shaking table to study the seismic performance of the structure has the following advantages [7]:

(1) Close to the actual simulation of the movement condition of the ground when the earthquake as well as the effect of earthquake on building structure.

(2) Through the strain gauge and other sensing devices, the loading state within the structure can be directly detected.

(3) Can be the most direct study of structural seismic response and damage mechanism, evaluate the overall seismic capacity of the structure.

(4) Can verify the validity and accuracy of the design calculation method.

(5) As for the development and research of the new structural system, the results of the shaking table test are important reference.

However, the vibration table test to determine the dynamic characteristics of the structure also 
has its shortcomings, mainly as follows:

(1) Gravity distortion, as most of the structure of the shaking table tests are carried out using the scale model, although artificial weight can solve these problems, but still cause the test results and the actual value of the deviation.

(2) The reduction of the model cause trouble to the selection of material, in the shaking table tests of some high-rise or ultra-high-level structure, because the size is too small, so cannot use raw materials, must find alternative materials, it is very difficult to find alternative materials that all the indicators meet similar conditions, generally use the materials that indicators are similar, but this may be cause the measurement results to be distorted.

(3) The simplification of complex prototyping structures and the simulation of component details are difficult to achieve, which can also result in some deviation.

(4) The factors that form the structural damping are many, but the general shaking table test model only focus on the simulation of the main component, while as for the live load which has a great effect on structural damping, the padding maintenance structure and so on only artificial quality to join the counterweight, this will also distort the damping test results.

\section{Conclusions}

The basic research of structural seismic design should be strengthened, prepare in advance for the revision of the design specification, the research and development of large shaking table should be strengthened, large-scale shaking table can carry out a lot of full-scale or large-scale model test, this model can be as realistic as possible to simulate the original structure of the test, reduce the size effect and gravity distortion effect. The theoretical breakthrough should also be strengthened, by proposing for different structures of data analysis and calculation methods to reduce the test error.

\section{References}

[1] Hongwang Ma, Xilin Lu: Journal of Tongji University (Natural Science). Vol. 12(2002), p. 1429 (in Chinese)

[2] Jian Jiang: Structural Engineers. Vol. 4(2008), p. 52 (in Chinese)

[3] Zhangchun Shen, Quanfeng Wang: Si Chuan Building Science. Vol. 3(2008), p. 136 (in Chinese)

[4] Feng Ren, Hongqiang Fang: Building Structure. Vol. S1 (2009), p. 626 (in Chinese)

[5] Yuhua Zhu, Hairong Huang, Yuxiang Xu: Structural Engineers. Vol. 5(2009), p. 149 (in Chinese)

[6] Yanhua Wang, Wenrang Cheng, Fei Lu, Zhongfan Chen: Earthquake Resistant Engineering and Retrofitting. Vol. 5(2007), p. 53 (in Chinese)

[7] Tao Li, Shenhua Li: Journal of Jiaying University (Natural Science). Vol. 2(2011), p. 49 (in Chinese)

[8] Zhen Zhao, Lili Xie: Journal of Earthquake Engineering and Engineering Vibration. Vol. 5(2011), p. 190 (in Chinese)

[9] Jieping Liu, Xiaodong Li, Lingxin Zhang: World Earthquake Engineering. Vol. 3(2006), p. 53 (in Chinese)

[10]Yuping Sun, Shichun Zhao, Lieping Ye: Building Structure. Vol. 5(2011),p. 13 (in Chinese) 